\title{
An Assessment of the "Policy View" in Foreign Aid under Asymmetric Information
}

\author{
Eskander Alvi and Debasri Mukherjee \\ Department of Economics, Western Michigan University, Kalamazoo, MI 49008, USA \\ Correspondence should be addressed to Eskander Alvi, eskander.alvi@wmich.edu \\ Received 15 August 2011; Accepted 25 September 2011 \\ Academic Editor: Miguel Leon-Ledesma
}

Copyright ( 2011 E. Alvi and D. Mukherjee. This is an open access article distributed under the Creative Commons Attribution License, which permits unrestricted use, distribution, and reproduction in any medium, provided the original work is properly cited.

The policy view, which argues that foreign aid is effective only in a good policy environment, suggests that aid ought to be given to countries with good policies. This has generated a lot of interest and controversy. We argue that the key recommendation of the policy view runs contrary to other prescriptions, particularly those that arise under asymmetric information. Inefficiencies that derive from information problems often require that policy makers do not base the amount of foreign assistance on the recipient's policy effort. This suggests that donors should be cautious in applying the policy view. We also briefly discuss problems that are likely to emerge in estimating aid's productivity given policy in the light of potential information problems.

\section{Introduction}

The view that foreign aid is effective only in the presence of good policy has had an enormous effect on donors and policy makers. A key implication is that aid should be channeled only to countries that have good policies. We refer to this as the "policy view." In this paper, we assess if the premise that aid should be conditional on policy makes good sense when information problems, particularly moral hazard and adverse selection, prevail. We argue that in the presence of such information problems it is often necessary that aid disbursement rules deviate from the policy view. Donors therefore ought to exercise caution in applying the policy view rather than embracing it as unreservedly valid. While there have been several empirical critiques of the policy view, some questioning the robustness of the key coefficients, others arguing about appropriate functional form or sample selection issues, the arguments we present here are mostly conceptual and deal with the policy prescription offered by the policy view versus those derived from information problems.

The debate on the policy view started in earnest with the Burnside and Dollar [1] paper, which argued that aid is effective only when the receiving country pursues good policy. Because the implications of the policy view are quite dramatic, potentially limiting or suspending aid to countries with poor policy performance, a lot of scrutiny has followed since. Opponents, notably Easterly et al. [2], have countered that the results of Burnside and Dollar [1] are not robust to the inclusion of more countries and additional years. There are several other papers that assessed these claims from a variety of different angles. ${ }^{1}$ While this literature has been largely empirical, our arguments assess the merits of the policy view from the conceptual side. ${ }^{2}$

\section{Moral Hazard and Adverse Selection}

To illustrate the impact of moral hazard and adverse section on aid, suppose that the donor neither observes policy undertaken by the recipient (the moral hazard problem) nor how badly each country is hurt by a disaster (the adverse selection problem). Consider the following simple setup to highlight the main arguments. Let the expected utility of a recipient country be $U=\alpha(p) u\left(y^{H}\right)+(1-\alpha(p)) u\left(y^{L}+A\right)-$ $C(p)$, where $y^{H}$ and $y^{L}$ denote high and low incomes with respective population ratios of $\alpha$ and $1-\alpha$, and $p$ denotes recipient country's policy effort which is unobservable to the donor. It is also assumed that aid per person, $A$, is given only to low-income households to capture poverty alleviation 
concerns, which is an important goal of foreign assistance. The presumption is that higher policy effort yields a higher ratio of high-income households, and therefore a smaller fraction of the population that needs aid transfers. Thus, $\alpha$ is strictly increasing and concave in $p$. The utility function $u$ satisfies the usual concavity assumptions, and $C(p)$ is the cost of undertaking policy where $C^{\prime}>0$ and $C^{\prime \prime}>0$.

The donor is risk-neutral and the poverty alleviation constraint is assumed to satisfy

$$
u\left(y^{L}+A\right) \geq \bar{U}
$$

where $\bar{U}$ is a minimum level of welfare that must be met. We assume that this constraint binds. Thus, aid given by the donor is $[(1-\alpha(p)) A]$, and the donor's cost rises when the recipient country chooses a lower policy effort.

The usual timeline we follow here is that the donor commits to an aid amount first, followed by the recipient choosing its policy effort, and then the aid disbursement occurs after the fraction of poor is observed. Because policy is not observed, following the standard moral hazard literature, $p$ satisfies the following condition:

$$
\alpha^{\prime}(p)\left[u\left(y^{H}\right)-u\left(y^{L}+A\right)\right]=C^{\prime}(p),
$$

that is, given the promised aid, the recipient country chooses a policy that satisfies equality of expected benefits and costs. We refer to this as the moral hazard constraint. It is useful to note that this condition implies that higher aid induces a lower policy effort.

Now consider the adverse selection problem where the recipient claims the extent of damage inflicted by a disaster, which we assume is not observed by the donor. Obviously, the recipient country has an incentive to exaggerate the extent of damage so as to claim larger aid. Let the extent of damage be denoted by the proportion of the high-income households being either $\alpha$ or $\beta$, capturing "less hurt," or "more hurt" respectively, where $\alpha>\beta$ but $\alpha^{\prime}(p)=\beta^{\prime}(p)$. That is, the less inflicted country has a higher percentage of the population in the high-income state, though it is assumed for ease of exposition that the marginal effects at any policy are the same. In terms of timing, as is common in this literature, we assume that the state of hurt is realized first, following the donor's promise of the aid amount, after which the recipient selects policy effort. As before, incomes are then realized and the poor are given aid.

The expected aid received by overstating is (1 $\alpha(p)) u\left(y^{L}+A^{\beta}\right)$, which is larger than what is received when reporting honestly: $(1-\alpha(p)) u\left(y^{L}+A^{\alpha}\right)$, where $A^{\beta}$ and $A^{\alpha}$ are aids given when $\beta$ and $\alpha$ are reported, respectively. ${ }^{3}$ Thus, to discourage misreporting, the incentive constraint is

$$
(1-\alpha(p)) u\left(y^{L}+A^{\alpha}\right) \geq(1-\alpha(p)) u\left(y^{L}+A^{\beta}\right) .
$$

But this requires that $A^{\alpha} \geq A^{\beta}$, contrary to the demands of the poverty alleviation constraint. This is the informational rent received by the less-hurt country. Interestingly, then the moral hazard constraint implies that the less-hurt country does not select a higher policy. This is seen below in the two possible scenarios, given that honest reporting is enforced: $\alpha^{\prime}(p)\left[u\left(y^{H}\right)-u\left(y^{L}+A^{\alpha}\right)\right]=C^{\prime}(p)$, when the less-hurt state realizes and $\beta^{\prime}(p)\left[u\left(y^{H}\right)-u\left(y^{L}+A^{\beta}\right)\right]=C^{\prime}(p)$, when the more-hurt state occurs. Given that $A^{\alpha} \geq A^{\beta}$ and $\alpha^{\prime}(p)=$ $\beta^{\prime}(p)$, it is evident that $p^{\alpha} \leq p^{\beta}$. That is, the high-aid-lesshurt country does not pursue a higher policy. ${ }^{4}$

It is possible to compare the two schemes-incentive versus pure poverty alleviation-in terms of their effect on policy and draw some general conclusions. The poverty alleviation constraint when binds suggests, say, $A^{\alpha}=a$ and $A^{\beta}=b$ where $b>a$. These are the lowest payments allowed under poverty alleviation when the state of hurt is observed. When the state of hurt is not observed and the incentive constraint is binding, we have $A^{\alpha}=A^{\beta}$. Thus, when both constraints bind we get $A^{\alpha}=A^{\beta}=b>a$, implying that the recipient always gets the higher amount $b$. The moral hazard constraint then implies $p^{\alpha}=p^{\beta}$. The less hurt country receives the same aid and pursues the same policy as the more hurt country, which is usually contrary to the desired policy targets conceived by the donor. Compared to the pure poverty alleviation scheme in the absence of information problems, the less hurt country receives more aid and selects lower policy. If the donor pays a larger rent, that is, the adverse selection constraint does not bind, the less hurt country receives even more aid and undertakes a policy effort that is lower than that of the more hurt county.

Interestingly, the association between aid and policy under asymmetric information problem scenario is always negative. Even excluding the adverse selection problem we have $A^{\alpha}=a<A^{\beta}=b$ and $p^{\alpha}>p^{\beta}$, which again shows a lack of positive association between aid and policy. Only when both the adverse selection and moral hazard constraints do not prevail, the policy view-positive association between aid and policy_emerges, where full information implies that the donor observes policy and the state of hurt and can allocate aid efficiently. In that case, for any given state of hurt, higher aid is associated with higher policy, and the more hurt receives more aid.

The empirical literature on aid addresses a variety of adverse incentive effects that weaken recipient country institutions. For example, Boone [12] finds support for the view that aid induces a larger government rather than enhancing investment or leading to improvements in human development indicators. Svensson [7] finds that aid raises corruption and rent-seeking activities, particularly when rival social groups vie for resources. Bräutigam and Knack [13] show that, in the context of Africa, aid is associated with declines in quality of governance and lower tax effort. Rajan and Subramanian [14] argue that aid weakens accountability of government to its citizens, leading to weaker governance. Economides et al. [15] show that aid encourages rentseeking activities and weakens domestic institutions, leading to inefficient use of resources, and Djankov et al. [16] find the negative effect of aid on GDP to be comparable to the "curse of natural resources." While there is not much in the way of direct evidence linking aid to subsequent policy outcomes, the indirect evidence in terms of negative association of aid with governance, rent seeking and quality of institutions is quite compelling. Like governance and 
quality of institutions, policy is difficult to monitor and provisioining of aid is likely to diminish the policy stance. It is useful to keep in mind that our claim about aid negatively impacting policy holds only when policy is not easily observed, otherwise conditioning on policy would be straightforward and more aid would not hurt policy.

\section{Concluding Remarks}

The prescriptive postulate of the policy view is that foreign assistance ought to be given to countries that have good economic policy. While this is a reasonable recommendation there are other competing prescriptions that arise from alternative economic scenarios. In this short paper, we discuss a few significant contrary ones that derive from informational problems and poverty alleviation concerns.

First, when moral hazard is prevalent such that policy is not fully observed or easily verified the recipient country has an incentive to underperform on the policy front, which translates to poor economic outcomes. Of key significance here is that policy cannot be treated as given or exogenous when moral hazard prevails. The suggestion of giving aid to countries with good policy (the policy view) can turn out to be counterproductive because the recipient country may respond by reducing its policy effort. To be exact, the prescription of the moral hazard view is that less, not more, aid is conducive to good policy and better economic outcomes. It suggests that trying to take advantage of good policy to enhance economic growth by giving aid could potentially undermine the aid-policy-growth relation, assuming it exists. This is very much akin to the wellknown Lucas critique which says that attempts to exploit the inflation-unemployment tradeoff would lead to its disappearance in the long run.

Second, adverse selection creates an incentive to misrepresent, that is, for a country to claim that it is badly hurt, following a disaster, when it is not. Incentive constraints require that an informational rent be given to the less hurt country. In effect, this may mean that a less hurt country receives more or equal aid compared to a more hurt country and, with moral hazard present, likely selects a lower policy effort that then leads to poor economic performance. This is also a scenario which contradicts the prescription that more aid should be given where the policy effort is higher. Because the donor observes the percentage of the poor (the outcome) rather than policy effort, the donor cannot punish the recipient after the fact by reducing aid, since poor performance may result from either bad luck or lower effort.

Third, though not shown in the model, where informational problems are not pertinent but poverty alleviation concerns prevail, a more hurt country warrants more aid but may be constrained to underperform on the policy front simply due to, say, damaged economic and political infrastructure. That more aid should follow better policy is again contradicted. Though the argument that poverty alleviation necessitates more aid is straightforward, the point here is that assistance is not always to be predicated on the basis of policy effort.
The above arguments also point to some potential difficulties on the empirical side. First, most measures of policy are likely to be imprecise since true policy effort is presumably unobserved or only observed with difficulty. This may be viewed as being similar to classical errors in variables problem, thereby suggesting the use of estimation techniques that address such issues. Second, recognition and a proxy for the state of information problems would enable appropriate conditioning and improve estimation results significantly. As discussed earlier, the severity of information problems dictates how seriously the incentives matter.

Another implication is that the empirical estimates of aid's productivity given policy may be compromised. The empirical literature in this area attempts to capture the effectiveness of aid in the presence of policy, specifically by estimating the cross partial $\partial^{2} y / \partial A \partial p$ in a panel regression, where $y, p$, and $A$ denote per capita income growth, policy, and aid, respectively. A positive coefficient implies that the marginal productivity of aid is higher when policy effort is high. The problem, of course, in the case of information concerns is that policy and the state of hurt are not easily observed and therefore not properly conditioned. If aid undermines policy effort due to moral hazard, or less hurt countries receive high aid by misrepresentation which then compromises their policy stance, the empirical result that aid is more productive in a good policy environment may be harder to establish. Furthermore, whereas empirical endogeneity problems mainly concern reverse causality between aid and growth in growth regressions, information problems focus on negative causality between aid and policy, which is not usually addressed in estimating the cross partial.

\section{Endnotes}

1. For recent references see Burnside and Dollar [1] and Dalgaard et al. [3]. Also, see Alvi et al. [4] where the authors try to explain the differing views by undertaking semiparametric estimation.

2. Some theoretical papers that discuss moral hazard and adverse selection issues pertaining to foreign aid, though not assessing the merits of the policy view, are Murshed and Sen [5], Murshed [6], Svensson [7-9], and Calmette and Kilkenny [10].

3. The reason is straightforward: by claiming that $\beta$ has occurred-that is, a larger proportion of the population is low-income- a larger aid is given to satisfy the poverty alleviation constraint. However, when $\beta$ actually occurs, the recipient country has no incentive to misreport.

4. It ought to be noted that the mechanism design literature suggests that some of the problems outlined here can be overcome if the donor knows the probability that a recipient is more hurt. See for example, Coate [11] and Calmette and Kilkenny [10] and the references cited there. While this would help mitigate some of the problems associated with moral hazard and adverse selection, especially when the shocks are recurring, it is unlikely that donors know the probability distribution 
of the many different types of shocks that afflict receiving countries many of which are unique and country specific. As such the inferior policy outcomes discussed here would likely continue to prevail.

\section{References}

[1] C. Burnside and D. Dollar, "Aid, policies, and growth," American Economic Review, vol. 90, no. 4, pp. 847-868, 2000.

[2] W. Easterly, R. Levine, and D. Roodman, "Aid, policies, and growth: comment," American Economic Review, vol. 94, no. 3, pp. 774-780, 2004.

[3] C. J. Dalgaard, H. Hansen, and F. Tarp, "On the empirics of foreign aid and growth," Economic Journal, vol. 114, no. 496, pp. F191-F216, 2004.

[4] E. Alvi, D. Mukherjee, and E. K. Shukralla, "Aid, policies, and growth in developing countries: a new look at the empirics," Southern Economic Journal, vol. 74, no. 3, pp. 693-706, 2008.

[5] S. M. Murshed and S. Sen, "Aid conditionality and military expenditure reduction in developing countries: models of asymmetric information," Economic Journal, vol. 105, no. 429, pp. 498-509, 1995.

[6] M. Murshed, "Strategic interaction, aid effectiveness and the formation of aid policies in donor nations," Journal of Development Economics, vol. 28, no. 1, pp. 189-203, 2003.

[7] J. Svensson, "When is foreign aid policy credible? Aid dependence and conditionality," Journal of Development Economics, vol. 61, no. 1, pp. 61-84, 2000.

[8] J. Svensson, "Foreign aid and rent-seeking," Journal of International Economics, vol. 51, no. 2, pp. 437-461, 2000.

[9] J. Svensson, "Why conditional aid does not work and what can be done about it?" Journal of Development Economics, vol. 70, no. 2, pp. 381-402, 2003.

[10] M. F. Calmette and M. Kilkenny, "International charity under asymmetric information," Economics Letters, vol. 74, no. 1, pp. 107-111, 2001.

[11] S. Coate, "Altruism, the Samaritan's dilemma, and government transfer policy," American Economic Review, vol. 85, no. 1, pp. 46-57, 1995.

[12] P. Boone, "Politics and the effectiveness of foreign aid," European Economic Review, vol. 40, no. 2, pp. 289-329, 1996.

[13] D. A. Bräutigam and S. Knack, "Foreign aid, institutions, and governance in sub-Saharan Africa," Economic Development and Cultural Change, vol. 52, no. 2, pp. 255-285, 2004.

[14] R. Rajan and A. Subramanian, "Does aid affect governance?" American Economic Review, vol. 97, no. 2, pp. 322-327, 2007.

[15] G. Economides, S. Kalyvitis, and A. Philippopoulos, "Does foreign aid distort incentives and hurt growth? Theory and evidence from 75 aid-recipient countries," Public Choice, vol. 134, no. 3-4, pp. 463-488, 2008.

[16] S. Djankov, J. G. Montalvo, and M. Reynal-Querol, "The curse of aid," Journal of Economic Growth, vol. 13, no. 3, pp. 169-194, 2008. 


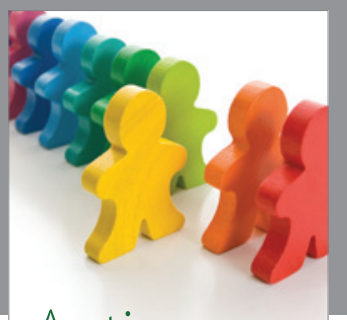

Autism

Research and Treatment
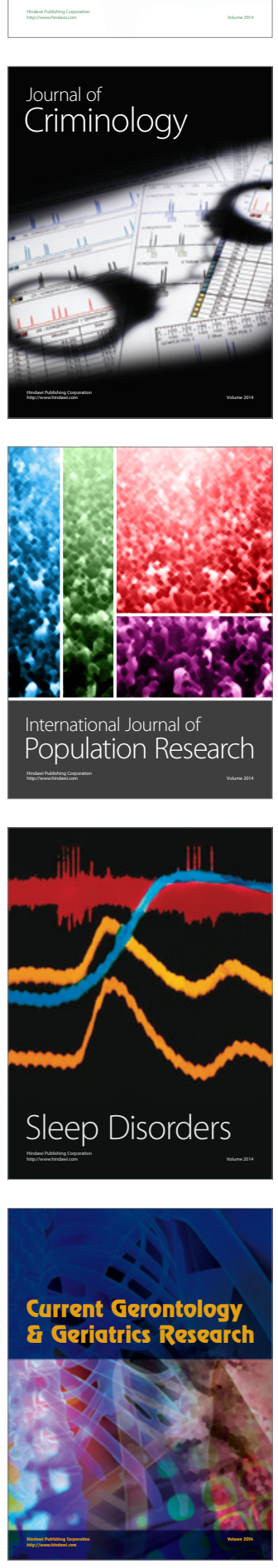
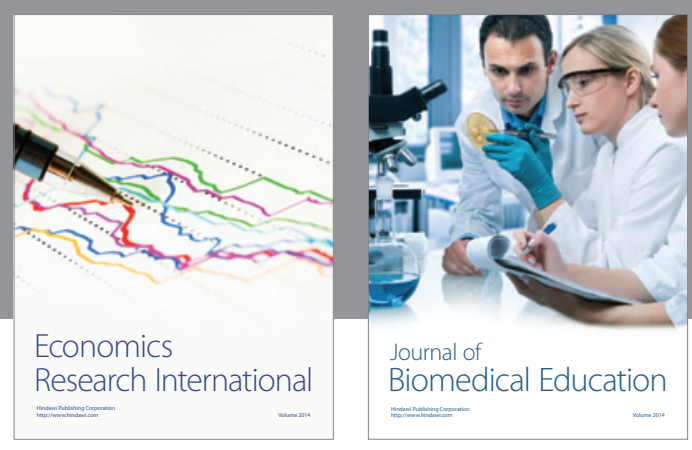

Journal of

Biomedical Education

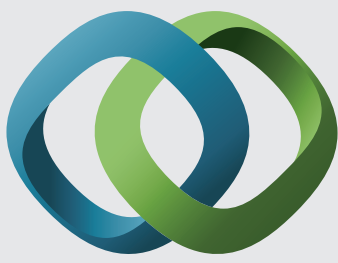

\section{Hindawi}

Submit your manuscripts at

http://www.hindawi.com
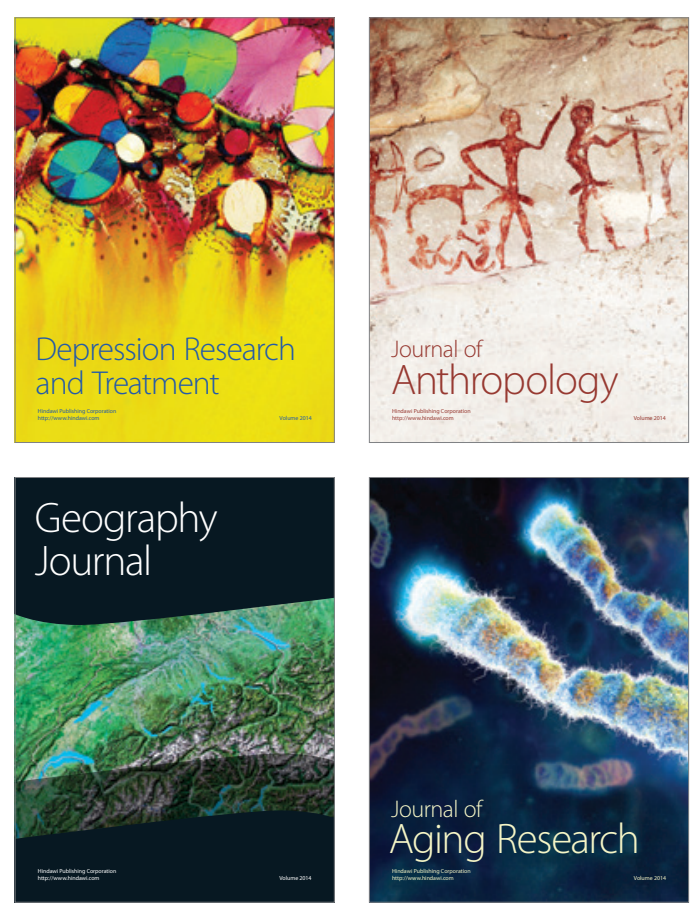

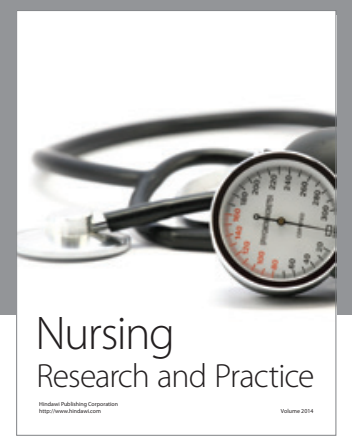

Nursing

Research and Practice

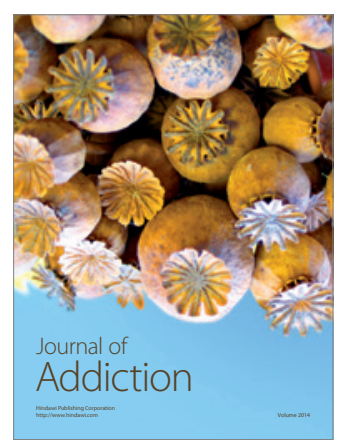

Child Development

Research

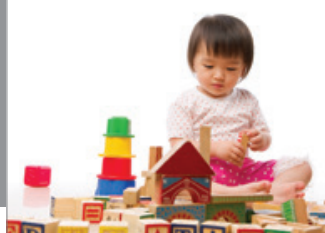

迥
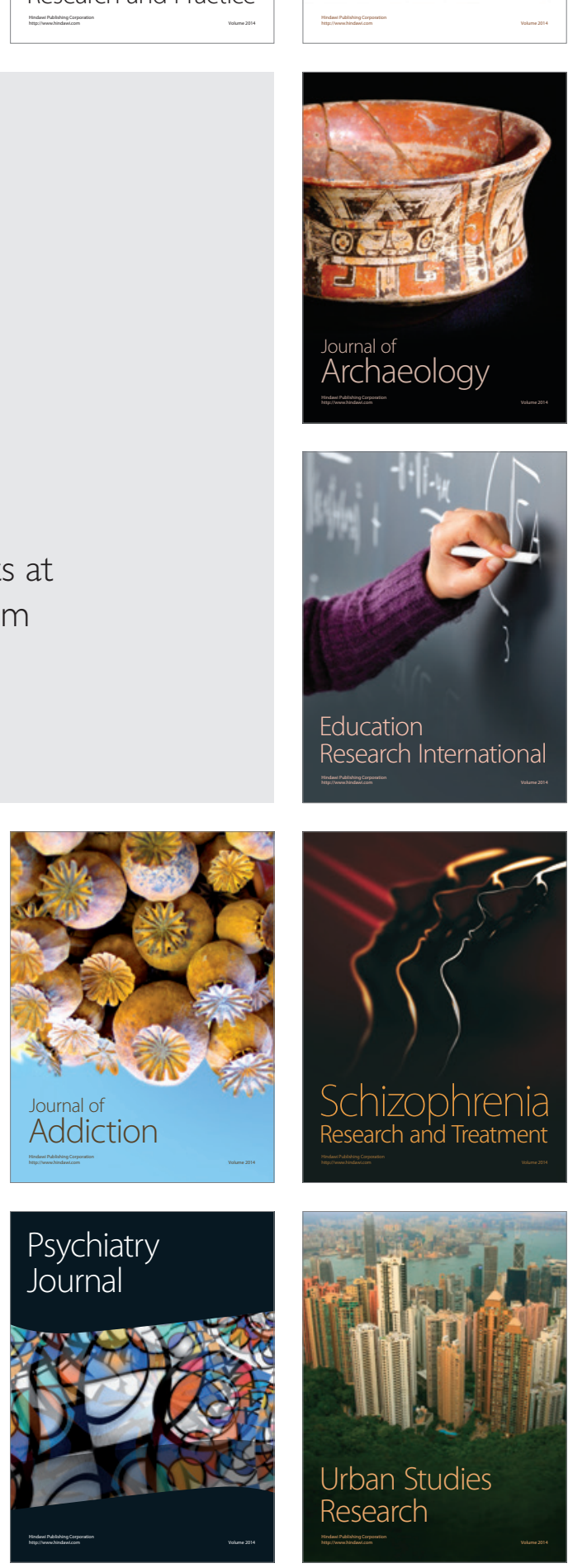